\begin{tabular}{lccc}
\hline VARIABLE & RA $\mathbf{n = 4 0}$ & Control $\mathbf{n = 4 0}$ & P - VALUE \\
\hline Age (years), mean (SD) & $58,5(9,4)$ & $58,5(9,4)$ & 0,998 \\
Sex (female), $\mathrm{n}(\%)$ & $30(75,0)$ & $30(75,0)$ & 1,000 \\
Rheumatoid factor, $\mathrm{n}(\%)$ & $32(80,0)$ & $2(5,0)$ & $<0,001$ \\
Anti-cyclic citrullinated peptide, $\mathrm{n}(\%)$ & $28(70,0)$ & $0(0,0)$ & $<0,001$ \\
DAS28 average value, mean (SD) & $3,6(0,5)$ & & - \\
Metotrexato (\%) & 72,5 & - & \\
biologic disease-modifying antirheumatic drugs (\%) & 37,5 & - & \\
\hline
\end{tabular}

Disclosure of Interests: Natalia Mena-Vázquez: None declared, Patricia RuizLimon: None declared, Isabel Moreno-Indias: None declared, Sara Manrique Arija Speakers bureau: ABBvie, MSD, Janssen, Lilly, Roche, Pfyzer, Novartis., Francisco Jose Tinahones: None declared, Antonio Fernandez-Nebro: None declared DOI: 10.1136/annrheumdis-2019-eular.3961

\section{AB0135 LEVELS OF MYOKINES AND RADIOGRAPHIC PROGRESSION IN PATIENTS WITH RHEUMATOID ARTHRITIS}

Jordana Miranda de Souza Silva ${ }^{1}$, Rafaela Cavalheiro Do Espírito Santo ${ }^{1}$, Deborah Negrão Gonçalo Dias ${ }^{2}$, Nayara Felicidade Thomas Braz ${ }^{3}$, Érica Leandro Marciano Vieira ${ }^{3}$, Eduarda Freitas ${ }^{1}$, Rafael Mendonça Da Silva Chakr ${ }^{1}$, Adriana Maria Kakehasi', Ricardo Xavier'. 'Laboratório de Doenças Autoimunes, Serviço de Reumatologia do Hospital de Clínicas de Porto Alegre, Universidade Federal do Rio Grande do Sul, Porto Alegre, Brazil; ${ }^{2}$ Hospital de Clínicas da Universidade Federal do Paraná, Curitiba, Brazil, ${ }^{3}$ Laboratório Interdisciplinar de Investigação Médica, Faculdade de Medicina da Universidade Federal de Minas Gerais, Belo Horizonte, Brazil; ${ }^{4}$ Universidade Federal de Minas Gerais, Belo Horizonte, Brazil

Background: Myokines, such as irisin and myostatin, are cytokines and growth factors mainly expressed in skeletal muscle, which is also their primary target tissue. They are released into circulation and exert a variety of systemic effects promoting crosstalk among different tissues [1]. Irisin is known to retrieve disuseinduced bone loss by stimulating the osteoblast pathways, while myostatin was demonstrated to be highly expressed in the synovial tissues of rheumatoid arthritis (RA) subjects, with direct role in osteoclastogenesis [2, 3].

Objectives: To investigate whether myokines serum levels can predict one-year radiographic progression in patients with $\mathrm{RA}$.

Methods: Forty female patients with RA, according to ACR/EULAR 2010 classification criteria, were included in the study. Blood samples were collected, and ELISA was used to measure serum levels of irisin and myostatin. Radiographs of hands and feet, taken within three months of the blood collection and a year later, were evaluated using the Sharp-van der Heijde $(\mathrm{SvH})$ score to verify the one-year radiographic progression. The RA activity was assessed by disease activity score based on evaluation of 28 joints (DAS28-ESR). Statistical analysis included Mann-Whitney $U$ test and Spearman correlation. A value of $p<0.05$ was considered significant.

Results: The mean age of RA patients was 53 years old, mean DAS28-ESR was 4.09 , mean disease duration was 11.2 years and mean BMI was $27.33 \mathrm{~kg} / \mathrm{m}^{2}$. The mean serum levels of irisin and myostatin were respectively $25.61 \pm 8.25 \mathrm{ng} / \mathrm{ml}$ and $3011.28 \pm 1271.11 \mathrm{pg} / \mathrm{ml}$. Considering radiographic progression, the mean values of SvH score were 28.3 and 31.3 in the baseline and after one year, respectively, resulting in a mean $\Delta \mathrm{SvH}$ of 3 . Over one year, $89.2 \%$ of the patients presented radiographic progression $(\Delta \mathrm{SvH}$ score $>0)$, and $10.8 \%$ presented rapid progression $(\Delta \mathrm{SvH}$ score $>5)$.

\begin{tabular}{lcc}
\hline SvH score & Irisin $(\mathrm{ng} / \mathrm{ml})$ & Myostatin $(\mathrm{pg} / \mathrm{ml})$ \\
\hline$\Delta \mathrm{SvH}=0$ & $31.66 \pm 10.66$ & $2943.94 \pm 719.96$ \\
$\Delta \mathrm{SvH}>0$ & $26.67 \pm 7.28$ & $2996.90 \pm 1356.66$ \\
$\Delta \mathrm{SvH}>5$ & $31.61 \pm 8.31$ & $3255.81 \pm 975.68$ \\
\hline
\end{tabular}

Conclusion: The serum levels of irisin and myostatin were not correlated with one-year radiographic progression. There was a tendency of increased myostatin levels in patients with rapid progression compared to patients with no progression. More studies are needed to investigate whether the myokine levels in the joint environment differ from the circulating concentration.

\section{REFERENCES}

[1] Giudice J, et al. Muscle as a paracrine and endocrine organ. Curr Opin Pharmacol. 2017 Jun;34:49-55.

[2] Colaianni G, et al. The myokine Irisin increases cortical bone mass. Proc Natl Acad Sci U S A. 2015 Sep 29;112(39):12157-62.

[3] Dankbar B, et al. Myostatin is a direct regulator of osteoclast differentiation and its inhibition reduces inflammatory joint destruction in mice. Nat Med. 2015 Sep;21(9):1085-90
Acknowledgement: Fundo de Incentivo à Pesquisa e Eventos do Hospital de Clínicas de Porto Alegre Coordenação de Aperfeiçoamento de Pessoal de Nível Superior

Disclosure of Interests: Jordana Miranda de Souza Silva: None declared, Rafaela Cavalheiro do Espírito Santo: None declared, Deborah Negrão Gonçalo Dias: None declared, Nayara Felicidade Thomas Braz: None declared, Érica Leandro Marciano Vieira: None declared, Eduarda Freitas: None declared, Rafael Mendonça da Silva Chakr: None declared, Adriana Maria Kakehasi: None declared, Ricardo Xavier Consultant for: Abbvie, Pfizer, Novartis, Janssen, Lilly, Roche

DOI: 10.1136/annrheumdis-2019-eular.6126

\section{AB0136 EVALUATION OF ANALGESIC ACTIVITY OF ALLOPURINOL AND FEBUXOSTAT IN EXPERIMENTAL ANALGESIC MODELS IN MICE}

\section{S Pal. SFCCP, Meerut, India}

Background: Allopurinol and febuxostat are xanthine oxidase inhibitor which are used in the treatment of hyperuricemia and gout. Pain is one of the important symptoms in gout patients.

Objectives: The present study is to evaluate the analgesic activity of allopurinol and febuxostat in two analgesic models in mice.

Methods: The analgesic activity of allopurinol $(39 \mathrm{mg} / \mathrm{kg}$ ) and febuxostat $(15.6$ $\mathrm{mg} / \mathrm{kg}$ ) was evaluated by using central analgesic model of Eddy's hot plate and peripheral analgesic model of acetic acid induced writhing. Both drugs were compared with the positive control, pentazocin for hot plate method \& aspirin for the Writhing method. Also both allopurinol and febuxostat were compared with each other.

Results: Both allopurinol and febuxostat showed significant increase in reaction time at various time periods in hot plate method \& also showed significant delay in onset of writhing as well as decrease in number of writhes in writhing method. As compared to positive control result allopurinol and febuxostat result were lower. Febuxostat shows better analgesic activity as compared to that of allopurinol. Conclusion: Allopurinol and febuxostat exhibited analgesic activity in both central and peripheral models of pain.

Disclosure of Interests: None declared

DOI: 10.1136/annrheumdis-2019-eular.862

\section{$\mathrm{AB} 0137$ \\ ROLE OF VIMENTIN AS A TARGET OF ANTIBODIES AGAINST CARBAMYLATED PROTEINS IN RHEUMATOID ARTHRITISPATIENTS}

Arbi Pecani $^{1}$, Tania Colasanti ${ }^{2}$, Cristiano Alessandri ${ }^{2}$, Martina Leopizzi ${ }^{2}$, Riccardo Mancini ${ }^{2}$, Fabrizio Conti ${ }^{2}$, Guido Valesini ${ }^{2}$, Francesca Romana Spinelli ${ }^{2}$. ${ }^{1}$ Rheumatology Unit, Department of Internal Medicine, University Hospital "Shefqet Ndroqi", Tirana, Albania; ${ }^{2}$ Rheumatology Unit, Department of Internal Medicine and Medical Specialties, Sapienza University of Rome, Policlinico Umberto I, Rome, Italy

Background: Patients with Rheumatoid Arthritis (RA) have an increased risk of cardiovascular diseases (CVD). Inflammation and autoantibodies indipendently promote endothelial dysfunction, which is the earliest, reversible stage of atherosclerosis. In vitro studies have demonstrated that antibodies against carbamylated proteins (anti-CarP), recently described in RA patients, can induce the production of proatherosclerotic molecules like Vascular Cell Adhesion Molecule (VCAM-1) and activate Interleukin-1 Receptor-Associated Kinase (IRAK-1), Nuclear Factor kB (NF-kB), inducible Nitric Oxide Synthase (iNOS) in endothelial cells $(1,2)$. Moreover, anti-CarP are associated to endothelial dysfunction and subclinical atherosclerosis in RA patients (3).

Objectives: Aims of the present study were: 1) to analyze the role of vimentin as a target of autoantibody response in the serum of patients with RA and 2) investigate the expression of vimentin and carbamylated proteins in endothelial cells. Methods: Consecutive RA patients were enrolled in this study. Vimentin was carbamylated and used as an antigen for the detection of anti-Vimentin Carbamylated antibodies (CarVim), through immunoenzymathic methods. Cells were incubated with anti-vimentin and carbamylated antibodies. The presence of vimentin and carbamylated proteins was investigated by immunofluorescence on the immortalized endothelial cell line EA.hy 926.

Results: Eighty-eight (88) RA patients were enrolled in this study ( $\mathrm{F}: \mathrm{M}=79: 9$ mean age $=56 \pm 13$ years). Anti-CarVim antibodies were present in $9 \%$ of the patients with a mean titre of di $442 \mathrm{aU} / \mathrm{ML}$ (IQR $303 \mathrm{aU} / \mathrm{ml})$. Vimentin and carbamylated proteins were detected in the endothelial cells by immunofluorescence (Figure 1). 